\title{
Die Elektricität in der Medicin-Studien von Dr. Hugo
}

v. Ziemssen. Zweite Haifte. Diagnostisch-Therapeutisclier Theil. Berlin, $\mathbf{1} 88_{5}$.

'This volume of 190 pages is the second half of a work of which the first half was published thirteen years ago. During that period many treatises on medical electricity have appeared, among them those of Meyer, Erb, Rosenthal-Bernhardt, and De Watteville. The author of the book before us displays considerable courage in challenging a comparison between his belated effort and the works just mentioned. That he was justified in doing this no one will doubt who is acquainted with the recent literature of the subject, and who will take the trouble to read Ziemssen's "Studies." While the first half of the work may have become antiquated (it is ont of print), the second half is fully up to date. Indeed, no one could wish for a better critical review of the most recent investigations in this branch of medical science than is to be found in this little book. It is refreshing to read the sober criticisms of a man who is himself a thorough investigator into the subject-matter of which he writes, and not a mere compiler.

Part II. of Prof. Ziemssen's treatise is subdivided into two main sections ; the first on electro-diagnosis, and the second on electrotherapeutics. In the introduction the author makes a strong plea for the use of the absolute galvanometer, and advances such arguments as are now familiar to all. There follow pregnant remarks on the various methods of electrical examination, and on the increased or diminished excitability of nerve and muscle, all of which lead up to the consideration of the reaction of degeneration. We have never read a clearer presentation of this difficult subject than the one here given. In addition to a lucid account of the clinical aspect of the RD, Ziemssen gives a minute description of the histological changes giving rise to the various phenomena of the reaction of degeneration.

As chief of a large clinic and medical institute, Prof. Ziemssen has been able to interest younger men-his assistants-in the many difficult problems still to be solved in connection with this very subject. Thus H. Gessler ("Die motorische Endplatte und ihre Bedeutung für die periphere Lähmung") has studied the relation of the nerve-endings in the muscles to the reaction of degeneration and to the process of regeneration. He finds that the "terminal nerve-plates seem to be to some extent independent of the nervous system, and in regard to their physiological function, to belong to the muscle rather than to the nerve. *** Among regenerative processes the regeneration of the terminal plates is the first to set in."

As regards the electrical phenomena of the RD, Ziemssen inclines to the view (which has been steadily gaining ground) that the modal changes in contraction are by far the most important; that in some cases of partial RD, in which the excitability of the nerve and the farado-muscular contractility are preserved, and in which there is no reversal of the normal formula of contraction, a sluggish contraction is the only and constant symptom. 
In view of the valuable additions which the author and his assistants have made to the study of the reaction of degeneration, it is rather surprising that he (the author) should have found it worth his while to protest against Erb's unmistakable claims to priority of discovery. In an able reply (in a recent number of the Berl. klin. Wochenschrift) Prof. Erb shows conclusively that the important facts of the typical RD were first established by him, and that, although Ziemssen and Weiss gave the first experimental proof of the partial RD in animals, Bernhardt and Erb were the first to prove this form of reaction in man.

But to return to the work in hand. Our author's views on electro-therapeutics are characterized by a conservative spirit that inspires confidence in all he has to say on this head. $\mathrm{He}$ believes the electrical current, if properly administered, to be a powerful therapeutic agent, but it is not a cure-all. The indications for its employment and for the current to be used are still empirical. "The best advice we can give is that the physician use both currents, the faradic and galvanic, in succession at each sitting." 'This advice is rather extreme, and the author himself is evidently very eager to depart from this rule, for he welcomes Enkelskjön's suggestions as a move in the right direction, although he does not feel warranted in accepting them until they shall have received further corroboration. In the matter of using weak or strong currents, Prof. Ziemssen inclines rather to Müller's views (referred to in the April number of this JOURNAL).

The various current methods of electro-therapeutical application are given in great detail. The customary and vague compliments are paid to the methods of general faradization and central galvanization. As for the electric bath, the author adheres closely to the views of Eulenburg and Lehr, and finds it a convenient means of general electrization. He is not particularly charmed wirh static electricity, and finds that the indications for its use are "rather vague," and hopes that men of sound judgment and of a critical turn of mind will give their attention to the methods of Franklinic electricity and to the method of general electrization. Careful electrization of the brain is recommended in organic as well as mental affections. The short chapter on the treatment of peripheral paralyses is full of good suggestions, and should be read by the student in connection with the chapter on the RD in the first section of this book.

Prof. Ziemssen's little volume will be enjoyed by the beginner (provided he shall have mastered as much as is contained in De Watteville's "Medical Electricity"), and still more by the neurologist who is anxious to be up to date, and who will compare this short treatise with certain bulky volumes which were considered standard books about ten years ago. It remains to be said that Prof. Ziemssen's style is good, and his language easy to understand.

B. S. 